\title{
O PROCESSO DE INSERÇÃO E EMPREGABILIDADE DE PESSOAS COM SÍNDROME DE DOWN: UM ESTUDO DE CASO
}

\author{
INTEGRATION AND EMPLOYABILITY PROCESSES OF \\ PEOPLE WITH DOWN SYNDROME: \\ A CASE STUDY
}

\author{
Larissa Aparecida Vieira* \\ Franciely Dias Machado** \\ Vera Lucia Martiniak ${ }^{* * *}$
}

\begin{abstract}
RESUMO
Este artigo aborda a discussão acerca do processo de inclusão de pessoas com deficiências na sociedade. Visto que não é somente nos espaços escolares que a inclusão deve acontecer, mas em todos os lugares, buscou-se nesta pesquisa investigar o processo de inserção e empregabilidade de pessoas com Síndrome de Down na vida profissional. Procurou-se compreender como se dá o encaminhamento para a efetivação em um trabalho formal, bem como a realidade dessas pessoas no contexto em que estão inseridas, compreendendo assim seu modo de vida, sua profissionalização e dificuldades encontradas ao longo da trajetória até ingressar como funcionário efetivo em uma empresa. Para isto, foi realizado um estudo no caso com um jovem que já está atuando no mercado formal. Para o desenvolvimento deste estudo realizou-se um levantamento bibliográfico das obras e documentos já existentes na área e que abordam o tema da inclusão, além de observações e entrevistas com o sujeito da pesquisa, com seus pais, professores da escola especializada e o seu empregador. Por fim, por meio dos resultados obtidos, foi possível compreender que uma pessoa com Síndrome de Down é capaz de aprender e se desenvolver, apesar de suas limitações, ingressando na vida profissional e desempenhando, assim, determinadas atividades, possibilitando um bom convívio social.
\end{abstract}

Palavras-chave: Inclusão. Síndrome de Down. Trabalho.

\begin{abstract}
This article discusses the inclusion of people with disabilities in society. Bearing in mind that inclusion should not be a process developed only in schools, this research sought to investigate the process of inclusion and employability of people with Down syndrome in the workplace. The study aimed at understanding the process of inclusion in formal jobs, the reality of these people in the context in which they operate, their way of life, their professionalism and difficulties
\end{abstract}

\footnotetext{
* Pedagoga formada pela Universidade Estadual de Ponta Grossa. E-mail: <larissavieira_20@hotmail.com>.

** Pedagoga formada pela Universidade Estadual de Ponta Grossa. E-mail: <franciely6@hotmail.com>.

*** Professora do Programa de Pós-Graduação em Educação da Universidade Estadual de Ponta Grossa. Pesquisadora do Grupo de Estudos e Pesquisas em História, Sociedade e Educação (HISTEDBR).
} 
until they are employed as regular workers in companies. For this, a study case involving a young woman who has been working in the formal market was carried out. This study included a literature review of the existing documents and studies that address the issue of inclusion, as well as observations and interviews with the research subject, with her parents, her school teachers in a special school as well as an interview with her employer. The results of the investigation contributed to the understanding that people with Down syndrome are able to learn and develop; despite their limitations they are able to have a working life and develop certain activities which provide a good social life.

Keywords: Inclusion. Down Syndrome. Work.

\section{Introdução}

A educação é um direito de todos, porém, quando se trata da educação de pessoas com necessidades educacionais especiais, ela ainda encontra sérias dificuldades para inclusão em escolas regulares, seja por preconceitos, medos e, ainda, em muitos casos, pela falta de informação e orientação dos profissionais da escola e da própria família.

Um dos aspectos da inclusão de pessoas com necessidades especiais se dá por meio da profissionalização, sendo um dos fatores significativos para a sua inserção em sociedade, pois revela a capacidade de cada um, que muitas vezes não é percebida nem dado o devido valor.

Tomando como foco central a discussão acerca da inclusão de pessoas com deficiências no mundo do trabalho, definiu-se para esta pesquisa a análise do processo de empregabilidade de pessoas com Síndrome de Down (SD) na empresa e seus reflexos no clima organizacional.

Sabe-se que o mercado de trabalho ainda é muito restrito às pessoas com deficiência e suas causas são diversas, tais como a falta de qualificação, a falta de esclarecimento e, acima de tudo, a falta de estímulos que facilitam a contratação. Percebe-se ainda que, apesar da aprovação de legislação própria, a inclusão social da pessoa com SD vai muito além dos ordenamentos legais. É necessário que cursos voltados para a profissionalização sejam oportunizados e que a contratação dessas pessoas pelas empresas seja estimulada, pois, independentemente de suas características físicas e singulares, são, antes de tudo, cidadãos e merecem respeito e dignidade.
Assim, este estudo tem como ponto de partida a contextualização histórica da Educação Especial e as formas de atendimentos que as pessoas com deficiência recebiam da sociedade. Num segundo momento, faz-se a caracterização da pessoa com SD - suas características físicas e biológicas - para favorecer o entendimento sobre a realização do estudo de caso. Ao final do texto, procura-se elencar algumas considerações a respeito da importância da empregabilidade e a necessidade de se estimular os empresários para a contratação de pessoas com SD a partir do desenvolvimento de um estudo de caso.

\section{Contextualizando a Educação Especial}

As primeiras iniciativas de atendimento às pessoas com algum tipo de deficiência mental ${ }^{1}$ surgiram por uma iniciativa de pesquisa biológica, com um atendimento clínico, não pedagógico. A pessoa era "estudada" e recebia tratamento médico, porém ainda não tinha direitos como os outros cidadãos. Esse atendimento acontecia em asilos, casas, instituições que eram ainda ambientes isolados.

A luta em favor dos direitos humanos dessas pessoas começou a ganhar espaço em 1948, por intermédio da Declaração Universal dos Direitos Humanos, sendo esta discussão retomada novamente em 1960 por meio de movimentos sociais. As discussões ganharam força novamente nas décadas de 1980 e 1990, e foi entre esses anos que começou a se cogitar a ideia de incluir na rede regular de ensino as

\footnotetext{
1 "A deficiência mental é entendida como funcionamento intelectual geral significativamente abaixo da média, oriundo do período de desenvolvimento, concomitante com limitações associadas a duas ou mais áreas da conduta adaptativa." (MEC, 1995).
} 
pessoas com necessidades especiais (VOIVODIC, 2004).

Com a Declaração de Salamanca, em 1994, deu-se um salto histórico para o processo de inclusão, pois foram discutidas políticas para a educação de alunos com necessidades educacionais especiais, principalmente a inclusão na rede regular de ensino. $\mathrm{O}$ foco foi assumir o compromisso de uma educação inclusiva - as escolas deveriam rever suas metodologias didáticas e adaptar a estrutura física e arquitetônica.

Nessa direção, em 2001, foram estipuladas, no Plano Nacional da Educação, as metas para a educação e propostas mudanças para que escolas adaptassem seus currículos, sua gestão e sua estrutura para oferecer uma educação de qualidade a todos, independentemente de suas necessidades e limitações.

Atualmente, a Educação Especial é assegurada nos artigos 58, 59 e 60 no Capítulo $\mathrm{V}$ da Lei de Diretrizes e Bases da Educação Nacional n ${ }^{\circ}$ 9394/1996, (LDB no 9394/96). A Educação Especial é o ramo da educação que se preocupa em atender alunos com necessidades especiais:

[...] o conceito de necessidades especiais é muito mais abrangente e não pode ser limitado a uma análise linear, centrada nas exigências do sujeito, apenas. Depreende-se, outrossim, que a identificação de necessidades especiais de pessoas ou de grupos impõe um recorte biológico, psicológico e social, não só para identificar a natureza das necessidades, bem como para estabelecer as condições de sua satisfação. (EDLER CARVALHO, 2003, p. 106).

Dessa forma, o atendimento na educação especial é garantido por lei e os alunos com necessidades especiais devem ser atendidos preferencialmente na escola regular. Além do atendimento educacional, esses alunos frequentam instituições que oferecem acompanhamento e tratamento médico, psicológico e social. Entretanto, apesar de a lei garantir a participação e compromisso do poder público governamental, ela não esclarece quais são os serviços educacionais que deveriam ser oferecidos aos alunos com necessidades especiais.

O que não ficou claro foi a natureza dos serviços educacionais a serem oferecidos, nem seus vínculos com o sistema geral de educação. $\mathrm{O}$ tratamento especial a elas preconizado sob as formas de bolsas de estudos, empréstimos e subvenções gerou muita polêmica pela indefinição das ações educativas oferecidas e dos critérios de eficiência da iniciativa privada e relativa à educação de excepcionais. (EDLER CARVALHO, 1998, p. 66).

A Educação Inclusiva é aquela que assegura uma educação de qualidade para todos os indivíduos, independentemente de idade, sexo, cultura ou necessidade. Visto que todos têm direito à educação, a ideia de Educação Inclusiva faz com que em uma mesma escola e, em sala de aula, haja interação, bem como a convivência de várias pessoas/alunos, ofertando a todos uma educação igualitária ao mesmo tempo que atende as particularidades de cada um.

O movimento mundial em direção à sistemas educacionais inclusivos indica uma nova visão da educação, que recupera seu caráter democrático através da adoção do compromisso legal com a oferta da Educação de Qualidade Para Todos, na qual a diversidade deve ser entendida e promovida como elemento enriquecedor do desenvolvimento pessoal e social. (DUK, 2005, p. 58).

Para que ocorra uma educação inclusiva para as pessoas com necessidades educacionais especiais, a instituição escolar deve ser adaptada - tanto sua estrutura física e suas metodologias didáticas quanto seus profissionais, que devem ser capazes de atender as particularidades de cada educando que se encontra incluído. Entretanto, se a escola somente atende alunos com necessidades educacionais especiais, mas não é totalmente adaptada e equipada para oferecer uma educação de qualidade, acontecerá uma integração desse aluno e não a inclusão do mesmo. Uma educação inclusiva de qualidade não propõe somente o convívio de crianças com necessidades com as demais, mas, sim, promove o ensino e assegura a aprendizagem com os requisitos necessários e a convivência em sociedade.

A Educação Inclusiva deve estar em evolução constante, partir do princípio de que todos os indivíduos têm direito ao acesso à educação e reconhecer que todos são capazes de aprender - no entanto, cada um tem seu tempo e sua forma. Deve também respeitar cada educando e criar estratégias para promover o ensino e a interação de todos.

No modelo organizacional que se construiu sob a influência do princípio da integração, os alunos 
deveriam adaptar-se às exigências da escola e, no da inclusão, a escola é que deve se adaptar às necessidades dos alunos.

Com o bom senso necessário, somado aos 48 anos de trabalho em educação concordo, plenamente, que a escola precisa ressignificar suas funções políticas, sociais e pedagógicas, adequando seus espaços físicos, melhorando as condições materiais de trabalho de todos os que nela atuam, estimulando neles a motivação, a atualização dos conhecimentos a capacidade crítica e reflexiva, enfim, aprimorando suas ações para garantir a aprendizagem e a participação de todos, em busca de atender as necessidades de qualquer aprendiz, sem discriminações. (EDLER CARVALHO, 2004, p. 67).

Uma educação inclusiva valoriza a diversidade; não a encara como obstáculo, mas sim como uma característica particular do aluno, o que não lhe impede de desenvolver, interagir com o meio e aprender os conteúdos que lhe é mediado nas relações sociais.

A inclusão não é um trabalho fácil de ser executado na escola, principalmente para os professores que estão em sala de aula, pois, além de garantir o aprendizado dos alunos com necessidades especiais, o professor ainda tem os demais alunos para trabalhar, garantindo a participação de todos e um ensino de qualidade.

O profissional da educação deve ter uma formação especializada que o prepare a fim de trabalhar com a diversidade e estar em constante atualização, sempre atento para enfrentar o imprevisto da prática pedagógica. Para tanto, deve utilizar materiais que atendam a individualidade de cada aluno para que ele possa aprender e se desenvolver, respondendo de modo eficaz ao ensino na escola. Os materiais didáticos são um forte instrumento de auxílio ao professor que podem garantir evoluções significativas no processo ensino-aprendizagem.

No caso da educação de crianças com Síndrome de Down, ${ }^{2}$ essa inclusão exige muito preparo do professor, uma vez que essas crianças se desenvolvem mais vagarosamente que as outras, e podem

\footnotetext{
${ }^{2}$ Segundo os resultados do Censo 2000 do Instituto Brasileiro de Geografia e Estatística (IBGE), aproximadamente $14,5 \%$ da população brasileira têm alguma deficiência física ou mental, ou seja, uma população de 24,5 milhões de pessoas. Estima-se que haja cerca de 300 mil pessoas que nasceram com a Síndrome de Down.
}

precisar de ajuda com mais frequência do que as demais.

\section{Caracterizando a criança com Síndrome de Down e o papel da escola}

A Trissomia do Cromossomo 21 ou Síndrome de Down é um distúrbio genético causado pela presença total ou parcial de um cromossomo 21 e é também a forma mais comum de atraso mental. Essa síndrome não é causa ou resultado de alguma gravidez de risco, drogas ou medicamentos ingeridos durante a gestação, mas uma disfunção cromossômica, sendo que os pais não são os responsáveis pela síndrome e não há possibilidade de evitá-la.

Os indivíduos com Síndrome de Down têm um processo de desenvolvimento mental e físico mais lento do que as outras pessoas. Sua coordenação motora, em muitos casos, é comprometida, acontecendo com atraso, o que reflete significativamente em algumas atividades do indivíduo. A criança com Síndrome de Down demora mais tempo do que o normal para conseguir andar, comer e escrever sem a ajuda de outra pessoa.

Desde o nascimento, as crianças com SD apresentam reações mais lentas do que as outras e, possivelmente, isso também altere sua relação com o ambiente. São os bebês menos responsivos em suas relações, talvez até devido ao atraso de seu desenvolvimento motor. O sorriso do bebê, por exemplo, depende do tônus muscular. (VOIVODIC, 2004, p. 44).

Devido as suas limitações, a criança com SD se desenvolverá mais lentamente que as demais e na sua aprendizagem será preciso utilizar metodologias e práticas educativas diferenciadas, bem como materiais didáticos adaptados que facilitem e estimulem o desenvolvimento motor. Isso não significa que a criança com SD inserida no ensino regular terá "matérias diferentes": ela terá, sim, as mesmas matérias, porém com uma metodologia adaptada e um atendimento profissional especializado.

O ambiente em que a criança está inserida tem forte influência sobre seu desenvolvimento; sendo assim, jogos, brincadeiras lúdicas e situações que promovam a interação da criança com mais pessoas tornam-se fundamentais. Se não for bem exercitada desde a infância, a dificuldade de coordenação 
motora influenciará no desenvolvimento de diversas atividades e no rendimento escolar da criança.

As pessoas que possuem essa síndrome possuem especificidades físicas que podem ser notadas facilmente. Geralmente apresentam as seguintes características: os olhos são pequenos com dobras internas, as orelhas são menores que o normal e mais baixas, o rosto tem um perfil achatado, possuem uma prega palmar única, têm a pele da nuca em excesso, o pescoço curto, os dedos das mãos e dos pés curtos, a ponte nasal achatada. Também, possuem uma estrutura mais baixa do que os outros, porém, um indivíduo com Síndrome de Down pode apresentar todas essas características ou apenas algumas delas (Voivodic, 2004).

Apesar de as pessoas com SD se desenvolverem e aprenderem conforme seu ritmo, isto não significa que são incapazes de ser alfabetizadas, de assimilar conteúdos e conseguir exercer uma profissão.

A maioria dos adolescentes passa por dificuldades para compreender as mudanças desta fase e o indivíduo com SD pode sentir ainda mais dificuldade se for visto e tratado com menosprezo pelas pessoas com quem convive. $\mathrm{Na}$ fase da adolescência, $\mathrm{o}$ indivíduo com $\mathrm{SD}$, apresentando ou não diferenças notáveis de temperamentos e atitudes, deve perceber que não é mais uma criança, que é capaz de aprender, agir e conviver com outras pessoas da mesma idade ou idades diferentes e vivenciar experiências com elas. Isso fará com que ele acredite em si mesmo, sentindo-se bem e não tendo receio de interagir com as demais pessoas da sociedade. A formação do autoconceito da pessoa com deficiência pode ser prejudicada pelas experiências repetidas de insucesso e pelos efeitos do preconceito (BRASIL, 1997).

Quando o adolescente adquire autoconfiança e quando chega à maturidade passa a desempenhar melhor algumas atividades, demonstrando habilidades que podem ser úteis no futuro. $\mathrm{Na}$ fase da adolescência é que se inicia a educação profissional desses indivíduos. A profissionalização ainda é bem recente, pois essas pessoas eram vistas pela sociedade como pessoas doentes, desprovidas de autonomia e competência, sendo assim consideradas incapazes de realizar um trabalho, não se encaixando, desta forma, nas exigências impostas pelo mercado.
As primeiras iniciativas de ensinar uma determinada atividade para os educandos com SD começaram com oficinas pedagógicas, cujos objetivos eram treinar e desenvolver habilidades nos alunos. O principal, no entanto, era ensinar determinadas tarefas sem a intenção de encaminhar o indivíduo para o mercado de trabalho. Os objetos confeccionados por eles eram vendidos e o dinheiro, na maioria das vezes, era usado pela instituição para comprar mais materiais para dar continuidade às atividades iniciadas. As oficinas pedagógicas, portanto, têm como objetivo o treinamento de habilidades e atitudes, e não consistem em uma atividade profissionalizante, embora tenham esta meta em perspectiva (BRASIL, 1997).

No entanto, o mercado de trabalho nos dias de hoje é um campo competitivo, tornando-se assim difícil para as pessoas conseguirem ingressar na carreira profissional. $\mathrm{O}$ ingresso no mundo do trabalho acaba por se tornar muito mais difícil para a pessoa com necessidade especial, pois ela dificilmente conseguirá sozinha ser aceita em uma empresa. Essa inserção geralmente ocorre por meio de encaminhamentos por parte das instituições; por sua vez, as empresas que recebem pessoas com necessidades especiais muitas vezes evitam empregar alguém com SD devido as suas limitações em relação à coordenação motora, linguagem oral, entre outras. Assim, prefere-se empregar pessoas com outros tipos de necessidades, como o indivíduo surdo, por exemplo, uma vez que o mesmo não possui as limitações da pessoa com SD.

O trabalho desempenhado pelo indivíduo com SD faz com que ele perceba a realidade tal como ela é - existem metas que precisam ser alcançadas.

Acreditamos que há relação entre a elaboração de metas realísticas e a motivação para o trabalho. Portanto, o desejo de ser incluído profissionalmente pode favorecer, nas pessoas com SD, o deslocamento do mundo imaginário para a realização de ações pertinentes ao mundo real. (MACHADO, 2009, p. 7).

Por meio da empregabilidade, o indivíduo passa a ser capaz de encarar mais facilmente os problemas encontrados no dia a dia, agindo de forma diferente diante deles e procurando soluções. É como se a pessoa precisasse trabalhar - algumas vezes não 
pelo salário - principalmente a fim de mostrar para todos que realmente é capaz, mesmo havendo quem a olhe com preconceito na sociedade.

\section{Procedimentos metodológicos}

Para o desenvolvimento desta pesquisa tomou-se como referência o processo de inclusão de um indivíduo com SD e o aprendizado para o exercício de uma atividade profissional. Neste estudo, optou-se pela pesquisa qualitativa, pois permite um aprofundamento de dimensões da vida social que podem ser analisadas, já que, segundo Moreira e Caleffe $(2006$, p. 73), “[...] a pesquisa qualitativa explora as características dos indivíduos e cenários que não podem ser facilmente descritos numericamente. O dado é frequentemente verbal e é coletado pela observação, descrição e gravação".

$\mathrm{Na}$ pesquisa qualitativa o pesquisador se coloca como um "descobridor ativo do significado das ações e das relações que se ocultam nas estruturas sociais [...]" (LEHFELD, 2004, p. 35).

O estudo de caso permitiu conhecer e compreender como foi a vida, a educação e a inserção do jovem no mercado de trabalho. O estudo de caso é uma pesquisa descritiva amplamente usada em muitas áreas. Um tipo de estudo de caso é a analise de trabalho (MOREIRA; CALEFFE, 2006).

O sujeito escolhido para o estudo e observação será denominado "A". Ele nasceu em uma família de classe média, porém nunca recebeu nenhum benefício social do governo porque não atende aos critérios estabelecidos para este programa.

Por meio das entrevistas realizadas, soube-se que esse indivíduo, desde a educação infantil, recebeu atendimento de profissionais especializados, tanto na área educacional quanto na área da saúde. No início da escolarização, frequentou a sala da Classe Especial em uma escola pública, bem como a Associação de Pais e Amigos dos Excepcionais (APAE) da cidade em que mora.

Na APAE, recebia o atendimento especializado de fisioterapeutas e fonoaudiólogos, uma vez por semana, em dias alternados, o que facilitou seu desenvolvimento motor e sua comunicação. Todos os professores eram especializados na área da Educação Especial e, por isto, proporcionaram metodologias e recursos diferenciados e específicos para suas necessidades. Recebeu, ainda, atendimento de um terapeuta ocupacional que visitava a associação duas vezes por mês. Apesar de todo o tratamento e acompanhamento médico, ele possui um pouco de dificuldade em relação à comunicação oral e também com a coordenação motora fina. Tem suas limitações e particularidades que precisam ser atendidas - nada que o impeça, no entanto, de conviver com todos, criando laços de amizade, trabalhando e conseguindo assim sua autonomia financeira.

Para atingir os objetivos propostos na pesquisa, foi necessário proceder ao planejamento das etapas de coleta de dados e à seleção do indivíduo pesquisado. Os dados foram coletados por meio de entrevistas semiestruturadas com questões abertas, que permitem que sejam adicionadas mais perguntas. Foi realizada uma análise de documentos (legislações, livros especializados) que serviram de suporte para a análise dos dados.

Os procedimentos de coleta de dados aqui utilizados foram:

1) Observação do sujeito;

2) Entrevistas com o indivíduo, sua família, o empregador e com os professores de uma instituição especializada.

$\mathrm{Na}$ primeira etapa, por meio da análise de documentos, procedeu-se o levantamento da legislação vigente em âmbito nacional a respeito da Educação Inclusiva. Essa análise subsidiou o referencial teórico e a análise de dados. Com a revisão de literatura é possível identificar as principais tendências de pesquisa na área de interesse, as eventuais lacunas e os conceitos importantes que estão sendo usados (MOREIRA; CALEFFE, 2006, p. 27).

Sendo assim, esses dados pesquisados foram interpretados e, em seguida, relacionados à realidade do caso estudado. Essa interpretação dos dados levantados possibilitou a compreensão das observações realizadas, pois a análise desse caso deu-se a partir desse levantamento dos dados escritos e da sua interpretação. Na etapa seguinte, foi realizada a observação em que foi possível perceber o comportamento e as atitudes do sujeito do caso estudado, o comportamento dos outros em relação a ele, bem como a relação entre eles. Por meio da observação foi possível também perceber suas habilidades, facilidades no trabalho e suas dificuldades. Essa observação permitiu que se compreendesse melhor o 
sujeito do caso, uma vez que se buscava entender sua inserção no ambiente de trabalho. Com a observação, nota-se a inserção desse sujeito no cotidiano da empresa. Essa observação possibilitou conhecer o contexto do indivíduo estudado e analisar detalhes impossíveis de se perceber com outro método de levantamento de dados.

Para finalizar essa etapa, procedeu-se a entrevista semiestruturada, formulada previamente, com perguntas abertas, seguindo um roteiro de questões a partir dos objetivos propostos para o estudo.

As vantagens desse tipo de coleta de dados é que ela permite certa liberdade tanto para o entrevistado como para o entrevistador, pois a entrevista flui como uma conversa, não constrangendo o entrevistado e deixando-o livre para as respostas. Cabe salientar que as entrevistas não foram gravadas, apenas registradas em papel.

\section{O processo de empregabilidade da pessoa com SD}

$\mathrm{Na}$ entrevista realizada com a família de "A", foi relatado que ele sempre foi um filho calmo, atencioso e obediente. Na idade escolar a maior dificuldade que ele encontrou se deu partir da $5^{\text {a }}$ série do ensino fundamental, devido à complexibilidade das matérias, a mudança de professor na sala a cada aula e o despreparo dos professores. Estes, segundo o relato da mãe do aluno, tinham medo de que, ao não entender a matéria, "A" ficasse nervoso, alterando seu comportamento, fazendo com que prosseguissem a explicação do conteúdo, mesmo restando dúvidas ao aluno. Outro fator negativo na escolarização foi a falta de materiais didáticos na escola, o que dificultou a aprendizagem nessa etapa do ensino.

$\mathrm{Na}$ escola especial em que estudava, "A" começou a participar de oficinas de educação profissionalizante e aprendia a realizar pequenas tarefas que estimulavam a coordenação motora, como trabalhar com artesanatos, jardinagens, entre outros. Durante esse período, fez estágio em uma empresa quando ainda tinha 17 anos. Nesse estágio, cumpria 20 horas semanais e realizava atividades como separar mercadorias, etiquetar caixas, empacotar mercadorias etc. $\mathrm{O}$ estágio durou nove meses e era acompanhado pela coordenação da instituição espe- cializada, que sempre mantinha contato com a empresa e realizava visitas ao local.

Hoje ele trabalha como recepcionista na Empresa $X$ na cidade em que mora. No início, quando começou a trabalhar, sua função era cuidar dos animais, lavar e pentear os mesmos. Depois de sete meses, a recepcionista parou de trabalhar e foi então que a Empresa $\mathrm{X}$ resolveu promovê-lo para este cargo.

A partir do momento em que começou a trabalhar com registro em carteira de trabalho, não teve mais vínculos com a escola especial e parou de participar das oficinas. Na observação realizada, percebe-se que "A" sente-se feliz e realizado com o trabalho, tem uma boa convivência com os colegas de empresa e desenvolveu uma relação de amizade também com os clientes da loja. Nota-se que ele ainda tem certa dificuldade com a linguagem oral, motivo pelo qual não atende o telefone.

"A" relatou um pouco das dificuldades que enfrentou ao começar a trabalhar. Contou, ainda, que sentia certo receio, pois era algo novo para ele e tinha medo de não conseguir:

"Eu ficava com medo de fazer as coisas erradas e de eles me xingarem por causa disso, mas agora não, agora eu já sei fazer as coisas."

Mas foi por meio do trabalho que ele aumentou sua autoconfiança e sua capacidade de raciocínio. Hoje " $A$ " consegue realizar pequenas adições e subtrações sozinho. Outra evolução visível foi a capacidade de memorizar os nomes das pessoas, pois antes ele sabia somente os de familiares e de alguns amigos, mas, depois que começou a trabalhar, ele consegue gravar os nomes de muitas pessoas, inclusive de clientes da loja.

É perceptível que quando a criança com SD recebe estímulos desde os primeiros anos de idade estabelece uma boa relação com a família e as demais pessoas com quem convive. Essa boa relação faz com que a pessoa sinta-se amada e acolhida.

As conquistas realizadas nos dois primeiros anos de vida da criança são a base da aprendizagem posterior e dão uma matriz de aprendizagem que será utilizada em idades mais avançadas. Portanto o trabalho de estimulação precoce é importante para propiciar o desenvolvimento do potencial da criança com SD. (VOIVODIC, 2004, p. 54). 
Esse estímulo influenciará significativamente no desenvolvimento e na aprendizagem da pessoa futuramente, pois as experiências e os ambientes nos quais convive são de extrema importância. Sendo assim, a forma como uma criança cresce e se desenvolve depende de variados fatores individuais, sociais e ambientais (BRASIL, 1997). A comunicação e a interação com outras pessoas no seu local de trabalho fez com que "A" desenvolvesse outras habilidades e construísse conhecimentos.

Os conceitos científicos se desenvolvem da vivência que a criança já traz do seu cotidiano, que será transportada para os conceitos científicos. As atividades cotidianas e o conteúdo de casa e da rua dão sentido ao desenvolvimento proposto na educação formal. (REILY, 2004, p. 21).

Pesquisas revelam que crianças com necessidades especiais, quando estão em convívio escolar com mais crianças, com necessidades especiais ou não, têm um avanço significativo em seu desenvolvimento. $\mathrm{O}$ trabalho realizado em grupo com as demais crianças é fator importante para que, futuramente, a pessoa com SD consiga atuar na vida em sociedade.

Melero (1997), num projeto realizado com crianças com SD em 1991, concluiu que o trabalho solidário e cooperativo em classes regulares possibilitou uma melhora substancial na relação mútua e no rendimento escolar de todos os alunos. Enfatizou a importância das diferenças entre as crianças e da interação entre elas na mesma classe para que a criança com SD tenha ganhos cognitivos. (VOIVODIC, 2004, p. 63).

Esses avanços alcançados ainda na convivência escolar farão com que a criança com SD consiga aos poucos tornar-se independente para tomar algumas iniciativas e realizar algumas atividades.

As brincadeiras infantis e os jogos que a família proporcionava a " $A$ " despertaram sua vontade de aprender a ler e escrever, fazendo com que ele, no início da idade escolar, se esforçasse para conseguir escrever, uma vez que sua coordenação motora era comprometida. $\mathrm{O}$ apoio dos pais, dos professores e dos profissionais da saúde que o atenderam, o motivaram e o estimularam fez com que as dificuldades na coordenação motora fossem amenizadas e que sua autoestima aumentasse.
Entretanto, seu ingresso no mercado de trabalho pela intermediação da escola, e também devido a sua doença, tornou-se mais difícil ainda, uma vez que para ser aceito em uma empresa são levados em conta muitos fatores. "As possibilidades atuais de acesso e permanência em um emprego cerca-se, antes de tudo, de aspectos políticos, econômicos e sociais. As condições individuais são importantes, mas não únicas." (BRASIL, 1997, p. 136).

As pessoas com SD em muitos casos são vistas como incompetentes para o trabalho, porém o apoio da família é essencial para sua inserção e sucesso.

A idéia alimentada, mesmo pela família, de que não pode ou não deve ter acesso ao trabalho tem muita influência no seu querer e no seu fazer. Desenvolver habilidade para o trabalho e aprender uma profissão dependem tanto de oportunidades ambientais como da extensão das limitações intelectuais e adaptativas da pessoa e determinam, em parte, a sua funcionalidade no contexto físico e social. (BRASIL, 1997, p. 137).

As limitações e dificuldades foram superadas e passou-se mais de um ano desde que "A" começou em um emprego formal.

\section{Conclusões}

Neste trabalho, procurou-se analisar o processo de inclusão e inserção no mercado de trabalho de um sujeito com SD, visto que esse ainda é um campo muito restrito para essas pessoas devido as suas necessidade e limitações.

Nos dias de hoje, apesar de todo o conhecimento que se tem sobre a Síndrome de Down, os indivíduos com esta síndrome ainda sofrem muito preconceito, sendo muitas vezes considerados incapazes e menosprezados pela sociedade. Com isso, a inserção dessas pessoas no mundo do trabalho ainda é mais difícil do que a inserção de uma pessoa com outro tipo de necessidade.

Outro fator que, em alguns casos, impede a pessoa com SD de exercer um trabalho formal é a existência de benefícios e programas do governo que lhes são oferecidos. O medo da não adaptação ao trabalho, do sujeito ou até mesmo da própria família, faz com que muitas dessas pessoas nunca trabalhem formalmente, pois, uma vez exercida uma 
profissão, o benefício do governo é cortado em definitivo.

No entanto, no caso estudado nesta pesquisa, é possível concluir que a pessoa com SD é capaz de trabalhar e conviver socialmente com outras pessoas. E esse convívio social é extremamente importante para o desenvolvimento e uma elevada autoestima do indivíduo. Quando ele é inserido na escola regular e recebe atendimento especializado, há o aperfeiçoamento de suas habilidades, de sua comunicação e coordenação motora, o que o estimula a se tornar um adulto independente e confiante nas suas atividades.

A profissionalização dos educandos com Síndrome de Down acontece por meio de oficinas pedagógicas nas instituições especializadas, as quais têm por objetivo estimular a comunicação e a coordenação motora, bem como contribuir para um melhor aproveitamento de suas habilidades. Para os alunos que já apresentam um melhor rendimento durante as atividades realizadas, existe a Educação Profissional, na qual os mesmos têm a possibilidade de adquirir uma profissão que lhes ofereça uma oportunidade de ingresso em um estágio. O estágio é acompanhado pela escola, que realiza visitas à empresa e analisa as atividades desenvolvidas pelo aluno. No decorrer do estágio, dependendo do desempenho do educando, o emprego poderá ser formalizado.

A inserção de um indivíduo com Síndrome de Down no mercado de trabalho, na maioria dos casos, ocorre através do contato entre escola especial e empresa e, neste caso, a própria escola se encarrega de encaminhar os alunos para determinadas empresas.

Há empresas que realizam parcerias com as escolas especiais. Assim, quando há uma vaga que possa ser preenchida por uma pessoa com necessidade especial, a empresa procura a escola, que, por sua vez, escolhe o educando que apresente as habilidades necessárias para preencher a vaga oferecida.

Quando não ocorre esse encaminhamento ou contato da escola com a empresa, o ingresso de pessoas com Síndrome de Down em uma empresa torna-se muito mais difícil devido, muitas vezes, à falta de informação por parte do empregador. Isso gera, assim, um receio em contratar uma pessoa com necessidade especial sem referências de sua situação educacional e clínica. Em alguns casos, a pessoa tem dificuldades em conseguir um emprego formal.

A partir desta pesquisa, pode-se perceber a importância de aprofundar e ampliar os estudos sobre a empregabilidade das pessoas com deficiência. Acredita-se que a inserção no trabalho seja uma das possibilidades de inclusão social, pois o contato direto e a interação com o público tornam-se importantes para que a sociedade perceba as possibilidades de atuação profissional dessa população.

Apesar de a pesquisa direcionar-se para um estudo de caso, verificou-se a importância da inserção e inclusão no trabalho, compreendendo que isto favorece a transposição da barreira do preconceito e oportuniza novos espaços para as pessoas com SD.

\section{Referências}

BRASIL, Secretaria de Educação Especial Deficiência mental, Educação Especial Deficiência mental. Brasília: SEESP, 1997.

Ministério da Educação, da Cultura e Desporto. Plano Nacional de Educação. Brasília: Inep, 2001.

Ministério da Educação, Cultura e Desporto. Lei de Diretrizes e Bases da Educação Nacional n ${ }^{\circ}$ 9.394, de 1996, Brasília: 1996.

UNESCO. Declaração de Salamanca. Sobre Princípios, Políticas e Práticas na Área das Necessidades Educativas Especiais. Disponível em: <http://portal.mec.gov.br/seesp/ arquivos/pdf/salamanca.pdf $>$ Acesso em: 10/08/2010.

DUK, Cynthia (org.). Educar na diversidade: material de formação docente. Brasília: Ministério da Educação. Secretaria de Educação especial, 2005.

EDLER CARVALHO, Rosita. A Nova LDB e a Educação Especial - Rio de Janeiro: WVA Ed., 1997.

Educação Inclusiva: com os pingos nos "is" Porto Alegre: Mediação, 2004.

Temas em educação especial - Rio de Janeiro: WVA Ed., 1998.

LEHFELD, Neide Aparecida de Souza; FILHO, Mário José. Prática de pesquisa, Franca: UNESP, 2004.

MACHADO, Maria Luiza Gomes; CHIARI, Brasilia Maria. Estudo das Habilidades Adaptativas Desenvolvidas por Jovens com Síndrome de Down Incluídos e não Incluídos no Mercado de Trabalho. Saúde Soc. São Paulo, v.18, n.4, p.652-661, 2009.

MOREIRA, Herivelto; CALEFFE, Luiz Gonzaga. Metodologia da pesquisa para o professor pesquisador, Rio de Janeiro: DP\&A, 2006. 
REILY, Lucia Helena. Escola Inclusiva: Linguagem e mediação, Campinas, SP: Papirus, 2004- (Série Educação Especial).

TEIXEIRA, Fernanda Cascaes; KUBO, Olga Mitsue. Características das interações entre alunos com Síndrome de Down e seus colegas de turma no sistema regular de ensino, Rev. Bras. Ed. Esp., Marília, Jan.-Abr., v.14, n.1, p.75-92, 2008.

VOIVODIC, Maria Antonieta M.A. Inclusão escolar de crianças com Síndrome de Down, Petrópolis, RJ: Vozes, 2004.

Data de Submissão: maio de 2012

Data de Aprovação: outubro de 2012 